Document downloaded from:

http://hdl.handle.net/10251/103323

This paper must be cited as:

Candel Bou, JJ.; Amado, JM.; Amigó, V.; Tobar, MJ. (2017). Effects of Laser Surface Melting on Ti 30Nb 2Sn Sintered Alloy. Advanced Engineering Materials. 19(6):1500640-11500640-4. doi:10.1002/adem.201500640

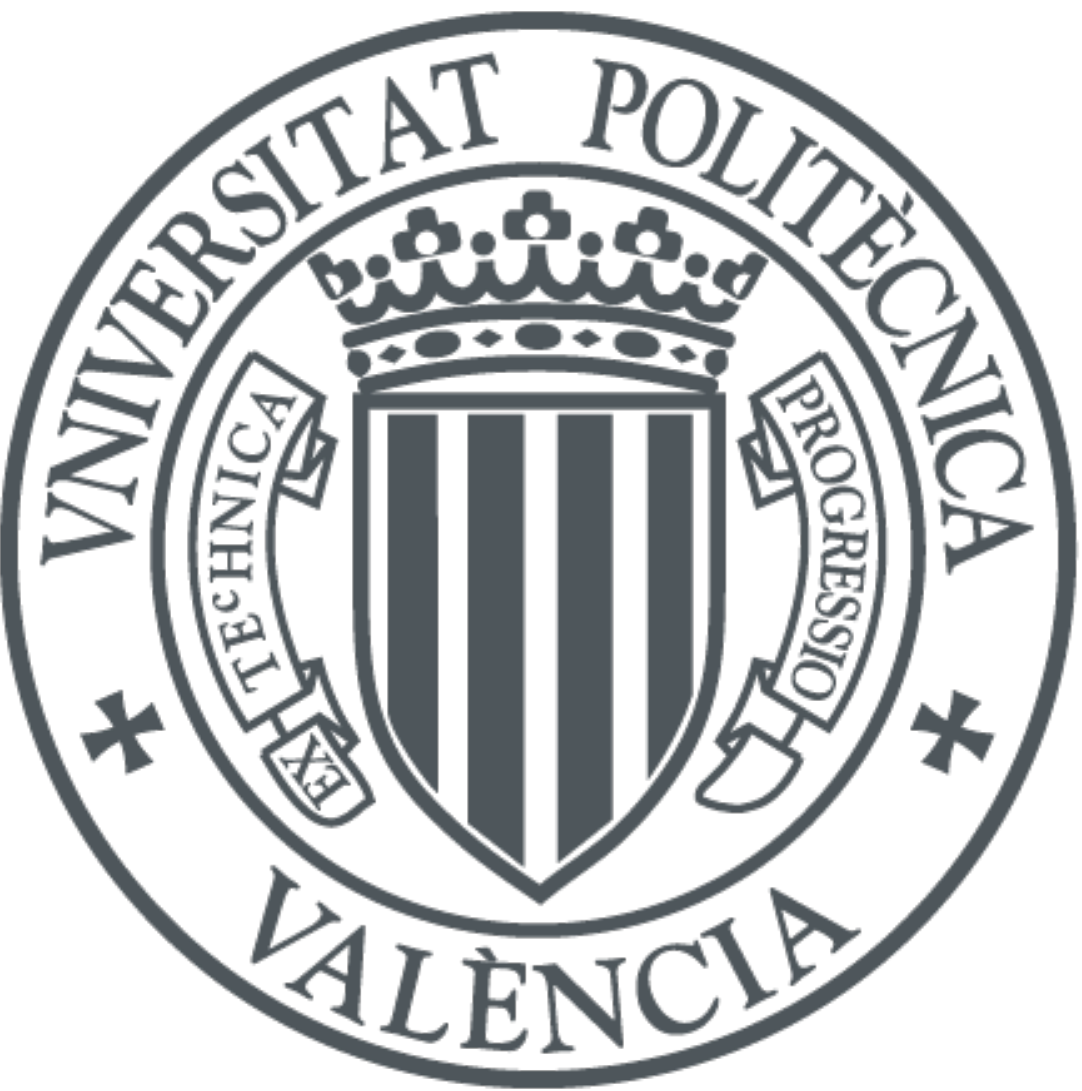

The final publication is available at

http://dx.doi.org/10.1002/adem.201500640

Copyright John Wiley \& Sons

Additional Information 


\title{
Effects of Laser Surface Melting on Ti-30Nb-2Sn Sintered Alloy
}

\author{
By Juan José Candel ${ }^{1}$, Jose Manuel Amado ${ }^{2}$, Vicente Amigó ${ }^{1}$ and María José \\ Tobar $^{2}$ \\ ${ }^{1}$ Department of Industrial Engineering II, Universidade da Coruña, Ferrol 15403, Spain \\ ${ }^{2}$ Materials Technology Institute, Universitat Politècnica de València, Valencia 46022, \\ Spain
}

\begin{abstract}
Laser surface melting (LSM) is used to simultaneously melt a thin layer and quench Ti$30 \mathrm{Nb}-2 \mathrm{Sn}$ substrate produced by powder metallurgy route. Results show LSM is useful to eliminate non-desirable open porosity and to reduce even more the Young Modulus. The best microstructure is achieved below the melting pool where high peak temperature combined with high cooling rate during laser processing is present. LSM retains beta titanium without traces of martensite or grain boundary alpha due to oxygen contamination.
\end{abstract}

\section{Introduction}

New beta titanium alloys based on non-toxic alloying elements like niobium, tantalum, and zirconium are very attractive for surgical implants manufacturing because of its outstanding biocompatibility combined with low elastic modulus which reduces bone reabsorption.[1] Against, the production of these highmelting pointmaterials using vacuum arc melting process and subsequent thermo-mechanical processing is sluggish and expensive.[2] And this fact is particularly dramatic for surgical implants manufacturing due to the associated secondary massive machining process to obtain the final shape.

Titanium powder metallurgy (PM) route is an interesting alternative because it allows producing near net-shape components starting from elemental powders and reducing machining waste.[3] Furthermore, Ti-PM allows reducing even more elastic modules thanks to the introduction of controlled porosity in the material.[4] However, other specific drawbacks have to be overcome to accomplish the mechanical requirements of biomedical implants, which are limited solid-state diffusion of beta refractory alloying elements and oxygen contamination of beta alloy due to either the initial oxygen content in raw materials or oxygen introduced during processing.

The combination of open porosity, heterogeneous microstructure, and the presence of oxygen remains the main warhorse to improve the fatigue resistance properties of titanium alloys produced by powder metallurgy.[5] The aim of this work is to demonstrate how laser surface melting (LSM)[6,7] can be a potential technique to melt a thin layer of Ti-PM components to close the open porosity and simultaneously quench the microstructure to reduce its Young's modulus. Then, metallurgical transformations and nanohardness-elastic modulus evaluation after precise LSM of $\mathrm{Ti}-30 \mathrm{Nb}-2 \mathrm{Sn}$ powder metallurgy alloy have been studied.

\section{Materials and Methods}

$\mathrm{Ti}-30 \mathrm{Nb}-2 \mathrm{Sn}$ (\%wt) beta titanium alloy has been our candidate because of its excellent corrosion resistance, biocompatibility, and other potential shape memory applications.[8] Rectangular samples of $30 \_10 \mathrm{~mm}$ and $10 \mathrm{~mm}$ in height were produced using the press and high vacuum sintering route.[9] Pressing was done using a double-effect floating die with 500MPa pressure and sintering was carried out at 1 573K during $7.2 \mathrm{ks}$ inside a high 
vacuum tubular furnace. Hidride-Dehidride Titanium powder (99.7\%wt purity with $0.254 \% w t$ O), Niobium powder (99.6\%wt purity with $0.3 \%$ wt O) and Tin powder (99.6\%wt purity with $0.35 \%$ wt $\mathrm{O}$ ), all of them with less than $45 \mathrm{mmmaximum}$ particle size, were used as raw materials. Powder blends were processed using a tumbler mixer under argon atmosphere in order to avoid oxidation.

Continuous wave Nd:YAG high power solid-state industrial laser system was used to melt a single track pool inside $\mathrm{Ti}-\mathrm{Nb}-\mathrm{Sn}$ samples. The energy profile of the laser beam $(\lambda=1064 \mathrm{~nm})$ corresponds to a "top-hat" distribution. Laser was defocused in order to obtain a beam diameter of $3.5 \mathrm{~mm}$ over the working plane. Defocusing distance $\mathrm{z}$ was calculated according to Equation 1, which relates the beam radius at $\mathrm{z}, \mathrm{r}(\mathrm{z})$, with the radius at beam waist $\mathrm{r}_{0}$ as:

$r(z)=r_{0} \sqrt{1+\left(\frac{z}{z_{\mathrm{R}}}\right)}$

Here, $\mathrm{z}_{\mathrm{R}}$ represents the effective Rayleigh, which accounts for quality factor $\mathrm{M}^{2}$ of the beam and is given by:

$$
z_{\mathrm{R}}=\frac{1}{M^{2}} \frac{\pi r_{0}^{2}}{\lambda}
$$

In our laser system, $\mathrm{r}_{0}$ and $\mathrm{M}^{2}$ are, respectively, $150 \mu \mathrm{m}$ and 35 . The maximum laser power $(\mathrm{P}=2000 \mathrm{~W})$ was applied with low scanning speed $\left(\mathrm{v}=5 \mathrm{mms}^{-1}\right)$. Parameters were chosen so as to obtain a wide melted depth of $\sim 500 \mathrm{~mm}$ using a single laser scan, therefore avoiding re-heating and overlapping effects. Laser system was equipped with a coaxial nozzle in order to provide helium-shielding atmosphere at $20 \mathrm{l} \cdot \mathrm{min}^{-1}$ flow rate.

The cross-section of the melting pool and the heat-affected zone (HAZ) was characterized using Optical Microscopy, under bright and polarized light illumination. Singular microstructures were captured at different points of the normal direction see Figure 1.

Both complementary techniques were selected to clearly depict titanium martensite inside beta grains and border grain reticular Ti- $\alpha$ phase. Electron Back Scattered Diffraction was used to discriminate crystallographically dissimilar phases by comparing the interplanar angles measured from the diffraction pattern, with calculated angles from a set of candidate phases and selecting the best fit. All the maps were captured at $1000 \mathrm{X}$ magnification to scan an area of $11360.72 \mu \mathrm{m}^{2}$ with a pixel size of $0.231 \mu \mathrm{m}^{2}$. The candidate phases were hexagonal titanium (to represent $\alpha$-Ti and $\varpi$-Ti), body centered cubic $(\beta-\mathrm{Ti})$ and orthorhombic $(\alpha$ "-Ti), see details in Table 1 . Finally, the Hardness $(\mathrm{H})$ and Young's Modulus (E) were analyzed using a Nanoindenter G-200 (Agilent Tech, USA). Indentations were performed on the cross-section of the polished sample using a previously calibrated diamond Berkovich tip. Tests were conducted using Continuous Stiffness Measurement (CSM) at $2 \mathrm{~nm}$ and $45 \mathrm{~Hz}$ harmonic oscillation. Experiments were limited to $500 \mathrm{~nm}$ of indentation depth. To ensure enough population of tests, an array of $20 \mathrm{X} 1$ indentations with $20 \mu \mathrm{m}$ spacing was performed for each microstructure type detected at Figure 2. The Poisson used for E calculus was 0.35 and the $\mathrm{H}$ and $\mathrm{E}$ average values were calculated in the range between the 300 and $500 \mathrm{~nm}$. These results were compared with that obtained at maximum load using the Oliver and Pharr method, fitting the unload curve. 


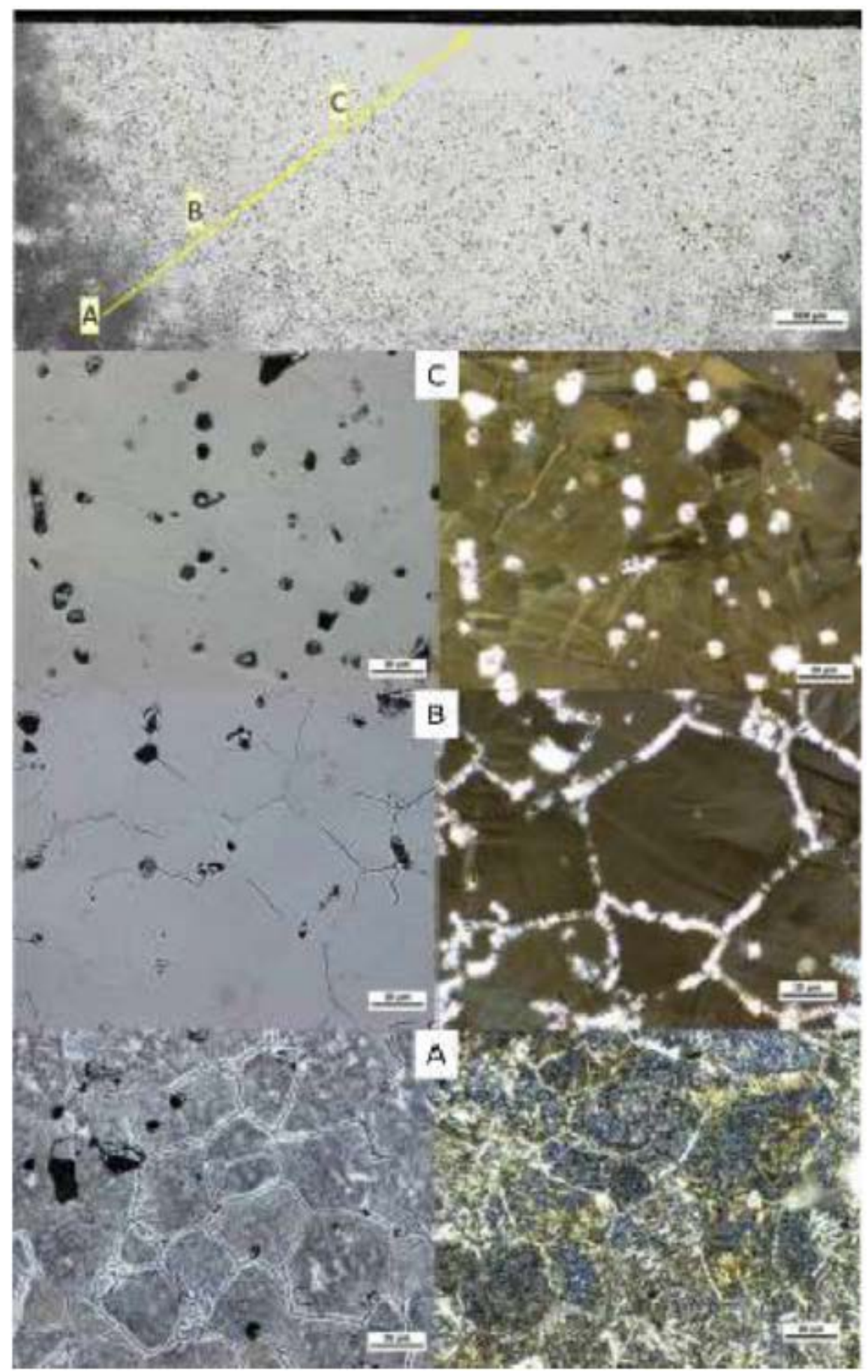

Fig. 1. Sample cross-section optical microscopy images showing microstructure evolution from non-affected surface to top surface of laser surface melting pool.

Table 1. Summary of the results of Figure 2 EBSD phase maps. Results in area percentage.

\begin{tabular}{lccr} 
Phase & A & B & C \\
\hline None & 15.8 & 16.9 & 15.2 \\
Ti-BCC & 54.2 & 36.9 & 60.3 \\
Orthorombic, CFACE & 18.5 & 34.1 & 17.7 \\
Ti-Hexagonal, PRIM & 11.5 & 12.1 & 6.8
\end{tabular}




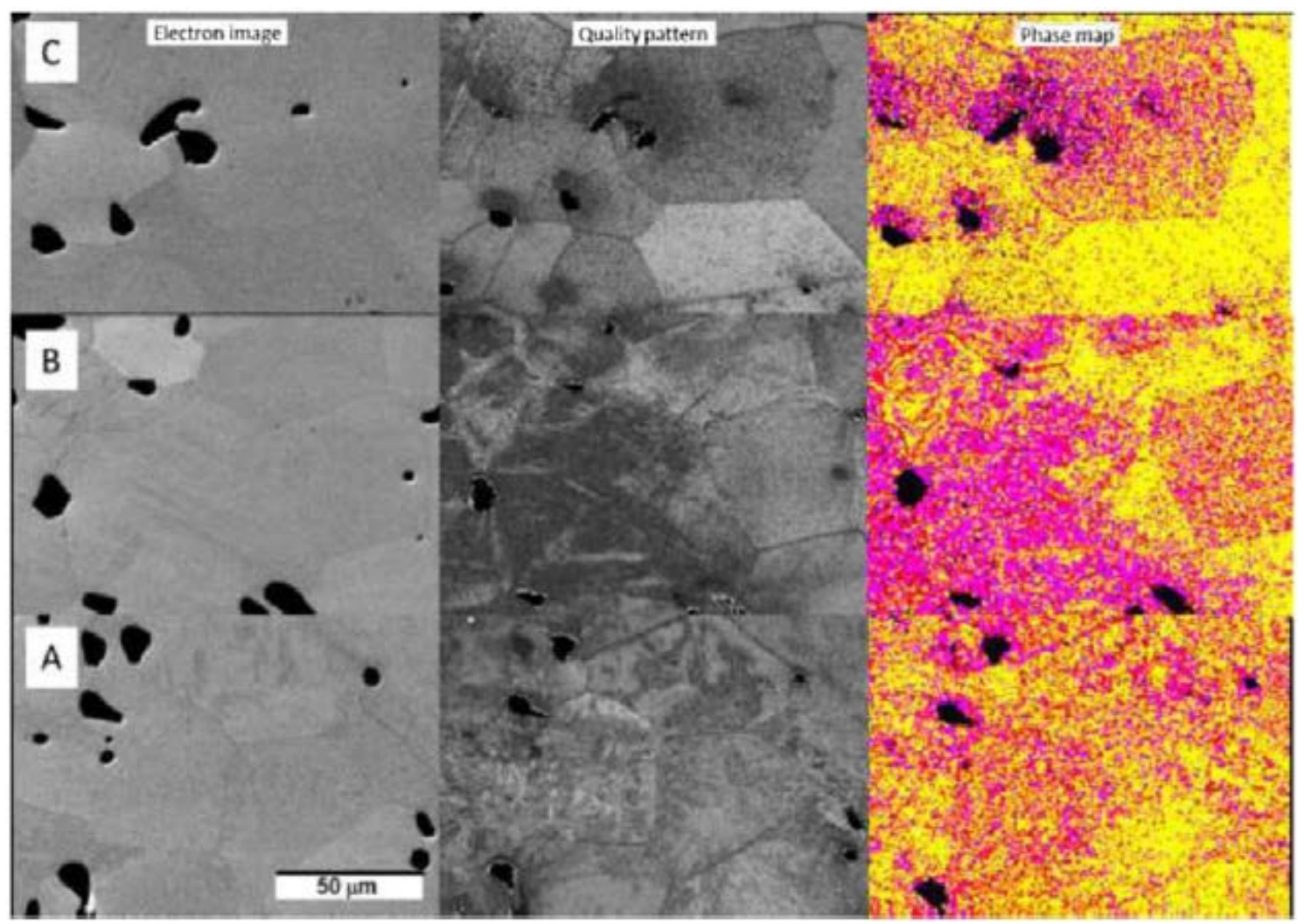

Fig. 2. EBSD analysis of specific microstructures in order to identify present phases: (A) PM substrate, (B) martensitic microstructure at $2.5 \mathrm{~mm}$ from top surface. (C) Equiaxed Ti-b microstructure at $1 \mathrm{~mm}$ from top surface. Phase map color label: yellow, BCC titanium; red, HC titanium; magenta, orthorhombic Ti-martensite.

\section{Results and Discussion}

Laser irradiation closes completely the inherent open porosity of powder metallurgy substrate inside the melting pool (Figure 1). Solidification microstructure is composed by extremely fine dendrites but has no special analysis interest; we will focus on solid-state transformations. Details of Figure 1 show the microstructure evolution from non-affected PM substrate (detail A) to the top region below the melting pool (detail C). The cooling process inside furnace, after sintering of $\mathrm{Ti}-30 \mathrm{Nb}-2 \mathrm{Sn}$ powder metallurgy substrate, retains $\beta$ phase due to the high-solute $\beta$ stabilizing element content of this alloy (Figure $1 \mathrm{~A})$. But a small quantity of nondesirable grain boundary a $(\mathrm{GB} \alpha)$ is formed due to the oxygen content of the initial powder and the low cooling rate imposed.[10] This hypothesis is confirmed by polarized light optical microscopy that clearly depicts $\alpha$ nucleation from border grain in the form of $\alpha$-widmanstatten.

At this moment, it is important to understand temperature profile inside titanium alloy when it is exposed to quasi-static LSM process. According to Mwobu et al., the maximum peaktemperature and cooling rate imposed depend on distance to top surface and isotherms have approximately the same shape than melting pool. The highest quenching severity is inside melting pool or at regions just below it because of higher peaktemperature combined with higher cooling rates applied in this zone.[11] Therefore, local metallurgical transformations that take place during cooling process will be connected with the relative position of each specific point to the laser because this fact determines: peak-temperature, time permanence above b-transus, and resulting cooling rate. Finally, it is important to remark that LSM quenches the material from peak-temperature above $2000 \mathrm{~K}$ and it reaches cooling rates bigger than $10^{3} \mathrm{ks}^{-1}$. Therefore, the present results are 
not comparable to those obtained with standard titanium quenching process from 1273 K.[10]

Thus, very clear needle-like plates of martensite inside the $\beta$ grain were observed at the bottom of the HAZ but GB $\alpha$ remains because quenching is not enough severe, see Figure 2B. Martensitic transformation is massive at this specific distance from the top surface (Figure 1B and 2B). Above this point, martensite percentage is progressively reduced to minimum just below melting pool due to the high local peak temperature combined with very high cooling rate achieved by laser that inhibits solid-state transformation (see Figure 2C). It is similar to austenite retained during laser processing of alloyed steels. Therefore, LSM process enhances the obtained microstructure eliminating the GB $\alpha$ intergranular network.

EBSD analysis results indicate that LSM changes the microstructure from a non-desirable phase distribution in PM substrate to a combination of Ti- $\beta$ and $\alpha$ " with a very small amount of ( $\alpha-\mathrm{Ti} / \varpi$ athermal) hexagonal phases below the melting pool, see Table 1 .

Finally, nanoindentation analysis confirms the beneficial effect of LSM on PM substrate. The $\mathrm{H}$ and E curves obtained for each microstructure analyzed are showed in Figure 3a. While E curves maintain constant values in depth, the $\mathrm{H}$ curves show a mild decay. This behavior is probably due to Indentation Size Effect (ISE) and due to the thin oxide layer hoped on the surface of sample.[12] The dispersion of data observed for each curve during the first $100 \mathrm{~nm}$ is provoked by the roundness of tip, the roughness of tested surface, and due to detection of individual phases and microstructures. Consequently, the average values were taken between the 300 and $500 \mathrm{~nm}$. This range assures us to avoid the undesirable surface effects while the dispersion of values due to the mechanical differences of phases distribution are preserved.

Summary of the results depicted in Figure 3b suggests that although substrate is progressively hardened, this phenomenon is accompanied by Young's modulus progressive reduction to reach minimum value below melting pool at $1000 \mu \mathrm{m}$ from top surface. Thus, LSM will reduce even more the Young Modulus mismatch between cortical bone and implant. An effective reduction from 82 to $72.5 \mathrm{GPa}$ can be achieved if $\mathrm{PM}$ is combined with LSM and this result is promising in comparison to other works done with laser cladding.[13] 


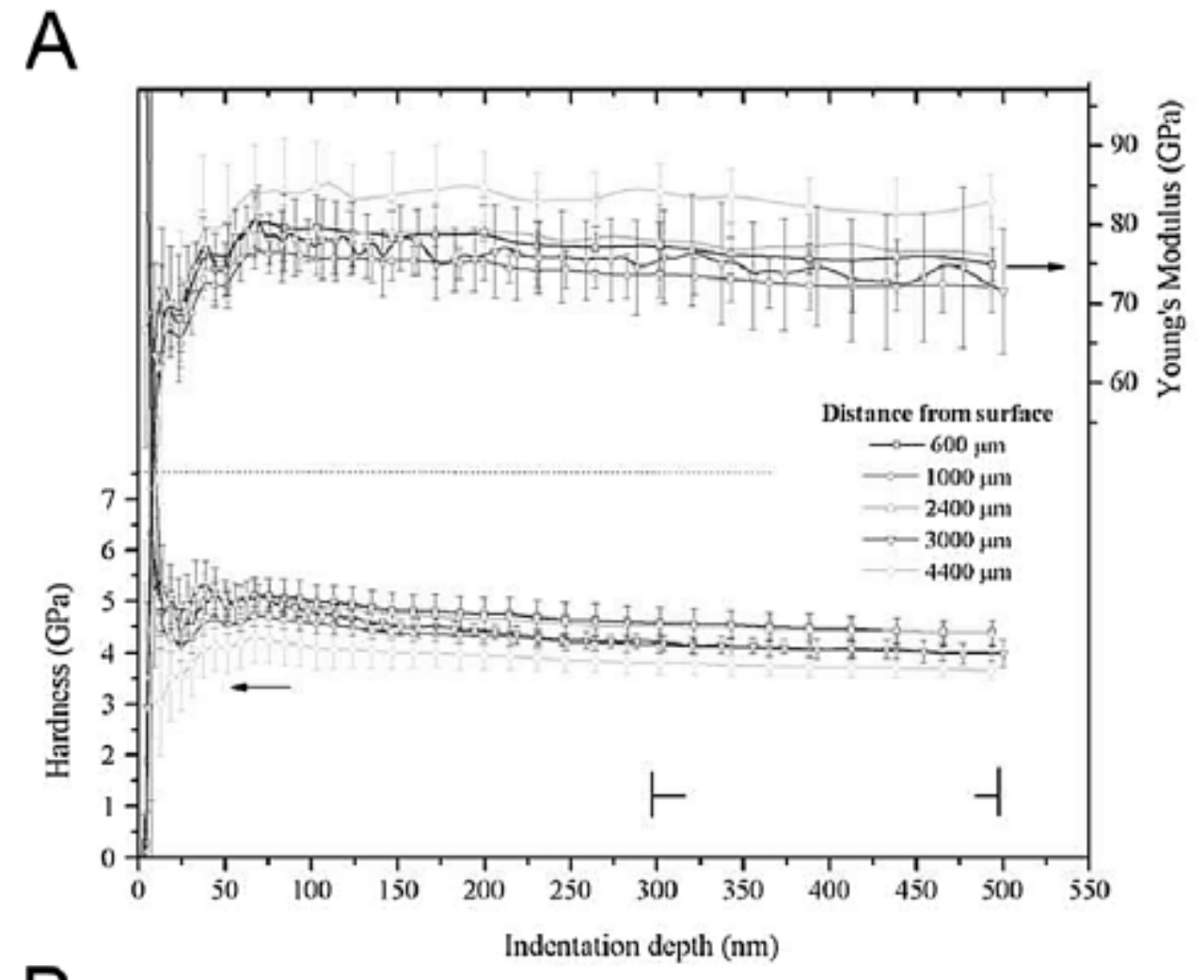

B

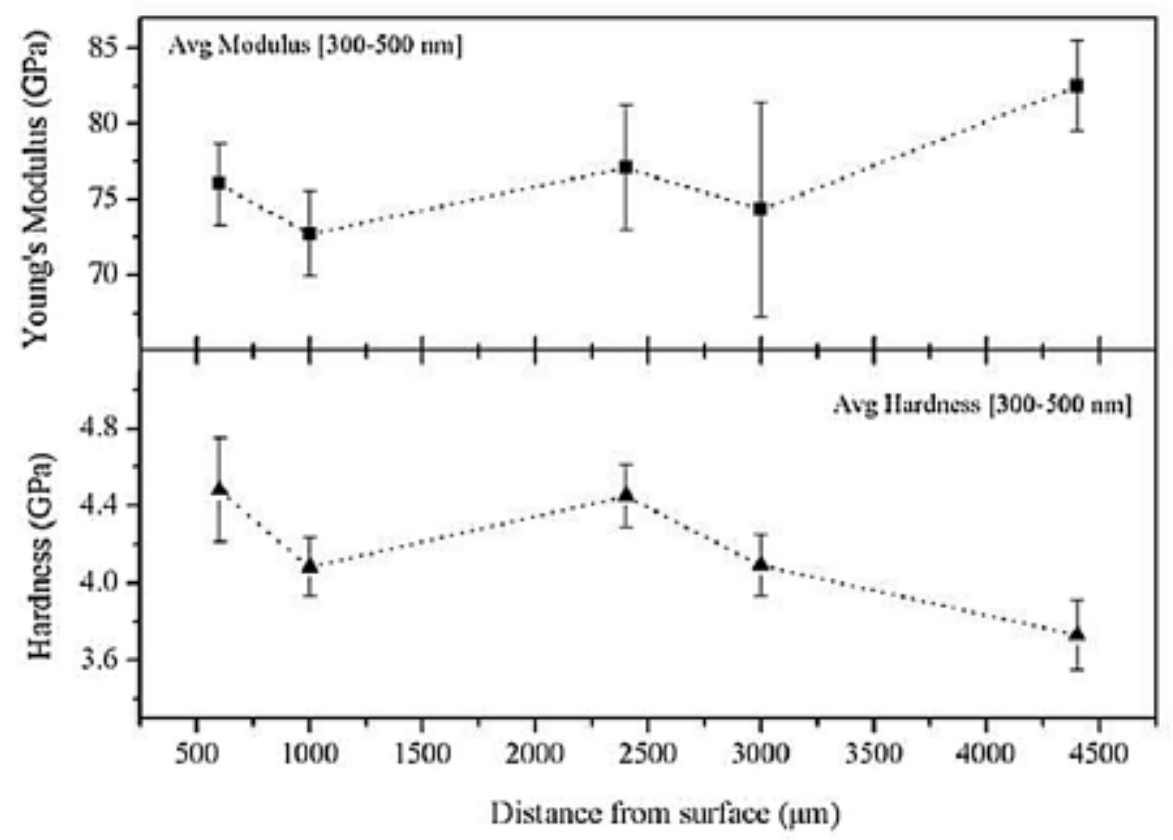

Fig. 3. Profiles in depth of the Modulus and Hardness results obtained by nanoindentation for each microstructure analyzed (a), and averaged values acquired between the 300 and $500 \mathrm{~nm}$ represented versus the distance from top melting pool surface (b).

\section{Conclusions}

In summary, thanks to the designed LSM process, it was possible to simultaneously close the open porosity and minimize elastic modulus of the Ti30Nb2Sn substrate. But in this case, it is crucial maximize the quenching severity of the laser processing, combining high laser irradiation and low scanning speed. Then, resultant microstructure consists of 
retained equiaxed beta grains without traces of needle-like martensite or grain boundary alpha. And for this reason a progressive reduction of Young modulus from non-affected substrate is achieved.

\section{Acknowledgments}

Thiswork is financially supported by Spanish Ministry of Science (Grant No. MAT201128492-C03-01 and BES-2009-013589) and PIB2010BZ-00448 International project.

\section{References}

[1] M. Geetha, A. K. Singh, R. Asokamani, A. K. Gogia, Prog. Mater. Sci. 2009, 5, 397.

[2] I. Weiss, S. L. Semiatin, Mater. Sci. Eng. A 1998, 243, 46.

[3] M. Quian, Int. J. Powder Metall. 2010, 46, 29.

[4] V. Brailovski, S. Prokoshkin, M. Gauthier, Mater. Sci. Eng. C 2011, 31, 643.

[5] H. Wang, Z. Z. Fang, P. Sun, Int. J. Powder Metall. 2010, 46, 45.

[6] E. Yasa, J. P. Kruth, Precis. Eng. 2010, 34, 101.

[7] E. Yasa, J. P. Kruth, J. Deckers, CIRPAnn. Manuf. Technol. 2011, 60, 263.

[8] [8] H. Y. Kim, Y. Ikehara, J. I. Kim, H. Hosoda, S. Miyazaki, Acta Mater. 2006, 54, 2419.

[9] E. B. Taddei, V. A. R. Henriques, C. R. M. Silva, Mat. Sci. Eng. C 2004, 24, 683.

[10] C. R. M. Afonso, G. T. Aleixo, A. J. Ramirez, R. Caram, Mat. Sci. Eng. C 2007, 27, 908.

[11] A. I. P. Mwobu, R. D. Rawlings, D. R. F.West, Acta Mater. 1999, 47, 631.

[12] X. Li, B. Bhushan, Mater. Charact. 2002, 48, 11.

[13] J. B. Fogagnolo, A. V. Rodrigues, V. Amigo, R. Caram, Scripta Mater. 2013, 68, 471. 